\title{
CORRELATION BETWEEN SERUM VITAMIN D LEVELS AND SEVERITY OF SCHIZOPHRENIA PATIENTS IN THE DR. SOETOMO HOSPITAL
}

\author{
Adil Dinata Simangunsong ${ }^{1}$, Aryati ${ }^{2}$, Azimatul Karimah ${ }^{3}$, Ferdy Royland Marpaung ${ }^{2}$ \\ ${ }^{1}$ Clinical Pathologist Specialization Program, Faculty of Medicine, Airlangga University/ Dr. Soetomo Hospital, Surabaya, Indonesia. \\ E-mail:adil.dinata79@gmail.com \\ 2 Department of Clinical Pathology, School of Medicine, Airlangga University/Dr.Soetomo Hospital, Surabaya, Indonesia. \\ E-mail:dr_aryati@yahoo.com \\ ${ }^{3}$ Department of Psychiatry, School of Medicine, Airlangga University/Dr. Soetomo Hospital, Surabaya, Indonesia
}

\begin{abstract}
Vitamin D deficiency is linked to various diseases such as kidney failure, liver damage, atherosclerosis, obesity, and psychiatric disorders such as depression and schizophrenia. This study aimed to analyze the correlation between serum vitamin D levels and schizophrenia severity. The subjects of this study were Schizophrenia patients who visited the Inpatient and Outpatient Clinic Department of Psychiatry of the Dr. Soetomo Hospital Surabaya. This research was a cross-sectional observational study, conducted in December 2017 - April 2018. The subjects consisted of 53 schizophrenia patients, vitamin D levels $<30 \mathrm{ng} / \mathrm{mL}$ was found in patients (35 (66.04\%); > $30 \mathrm{ng} / \mathrm{mL}$ (18 (33.96\%). Serum vitamin $D$ levels tested by Enzyme-Linked Fluorescent Assay (ELFA) method using Vidas. The severity of schizophrenia was measured using a Positive and Negative Syndrome Scale (PANSS) score. Mean serum vitamin D levels in schizophrenia were $23.45 \pm 9.16 \mathrm{ng} / \mathrm{mL}$, mean serum vitamin D levels in males were $24.36 \pm 9.80 \mathrm{ng} / \mathrm{mL}$, and females $21.96 \pm 7.98 \mathrm{ng} / \mathrm{mL}$. The mean serum vitamin D level and PANSS scores of positive symptoms were $16.42 \pm 8.50$. The mean serum vitamin D level and PANSS scores of negative symptoms were $15.60 \pm 6.12$. The mean serum vitamin D level and PANSS scores of general psychopathology symptoms were $29.51 \pm 10.29$. The statistical results showed no association between vitamin D levels and PANSS scores. This study indicated low serum vitamin $D$ levels in schizophrenia. There was no association between serum vitamin $D$ levels and the severity of schizophrenia using PANSS scores.
\end{abstract}

Key words: Vitamin D, schizophrenia, PANSS score

\section{INTRODUCTION}

Vitamin $D$ is a steroid hormone, it is not only referred to as a vitamin, because vitamin $D$ could be synthesized by skin exposed to Ultra Violet B (UVB) radiation. Vitamin $D$ has two forms: ergocalciferol (vitamin D2) found in fish and plants and cholecalciferol (vitamin D3) synthesized in the skin from exposure to sunlight. ${ }^{1}$ Previous studies suggested vitamin D had also been linked to mental illnesses including Alzheimer's disease, major depression, psychosis, and premenstrual mood disorder, so it was concluded that vitamin D had an important role in the central nervous system in the development and function of the normal nerves. ${ }^{2}$

Schizophrenia is a group of neuropsychiatric disorders characterized by symptoms such as hallucinations, delusions, confused thinking, and disorganization of speech. ${ }^{3}$ The early and chronic onset of the disease causes problems in patients and families. The relapse that occurs can show positive symptoms such as delusions, suspicion, and hallucinations. ${ }^{4}$ Surveys have been carried out in various countries, and almost all show incidence rates per year of schizophrenia in adults within a quite narrow range between 0.1-0.4 per 1,000 populations. ${ }^{5}$ Prevalence of adults ranges between 1-17 people per 1,000 populations. The number of people with schizophrenia around the world can be estimated at 29 million, of whom 20 million live in developing countries. ${ }^{6}$ Schizophrenia is caused by a neurodevelopmental defect that disrupts early brain formation during specific but as yet unknown.? Studies of rats with vitamin D deficiencies showed histologic and anatomic changes in brain development as a result of vitamin $D$ deficiencies. In particular, studies showed a narrowing of the anterior and posterior cingulate and medial and occipital cortical areas. ${ }^{8}$ Vitamin $\mathrm{D}$ rich diets or vitamin $D$ supplements have resulted in positive outcomes when added to treatment for some psychiatric illnesses like major depression, 
Alzheimer's disease, and premenstrual dysphoric syndrome. A correlation between schizophrenia and low levels of vitamin $D$ during the prenatal period and the early childhood have been well demonstrated, However, the influence of low vitamin D status on symptom severity in patients with schizophrenia has only recently begun to be investigated. Studies in the literature that compare vitamin $D$ levels and disease severity have obtained varying results. ${ }^{9,10}$

Geographical differences, different phases of the occurrence of disorders such as acute phase, chronic, acute exacerbations and remission, seasons of taking blood samples, history of psychoactive drugs use, age, sex, occupation, Body Mass Index (BMI) and sunlight exposure can affect vitamin $D$ levels in the body. The primary management strategy for schizophrenia is the antipsychotic drug although this approach is less effective in overcoming the negative symptoms and the side effects of the drug can harm and weaken the patients. ${ }^{11-13}$ Oxidative stress and immune responses occur in schizophrenia patients, so in some studies, it has been suggested that impaired physiologic mechanisms can be corrected with nutritional intervention. Nutrition approaches as an adjuvant and antipsychotic drugs are expected to be useful in the management of schizophrenia. ${ }^{14}$ This study aimed to analyze the association of serum vitamin D levels and the severity of schizophrenia using PANSS scores.

\section{METHODS}

This research was an observational analytical study with cross-sectional design by examining vitamin $D$ levels in schizophrenia patients and measuring the severity of schizophrenia symptoms. The study conducted in December 2017-April 2018 in Inpatient and Outpatient Clinical Medical Psychiatric Dr. Soetomo Hospital Surabaya. The diagnosis of schizophrenia, according to the Classification Guidelines and Diagnostic of Mental Disorders III (PPDGJ III) was performed by a Psychiatry consultant. The Positive and Negative Syndrome Scale (PANSS) is one of the most common scales in clinical studies for measuring symptom severity in patients with schizophrenia, seven items are measuring positive symptoms, seven for negative symptoms and 16 items corresponding to general symptoms. The PANSS consists of 30 items measuring specific symptoms, each item ranging from 1 (absent) to 7 (extreme). Residents of psychiatry performed evaluation of PANSS score under the supervision of a psychiatry consultant.
Subjects of the study were schizophrenia patients who met the inclusion criteria aged 18-50 years, willing to participate following written informed consent sheet, signed by parent or guardian or person in charge, before following any procedure related to the studied.

The exclusion criteria were schizophrenia patients taking antiretroviral drugs, rifampicin, anti-epilepsy, or other drugs related to calcium, phosphate, and vitamin D metabolism. Schizophrenic patients with calcium or vitamin D supplements; Schizophrenia patients with liver disorders; Renal insufficiency; Parathyroid hormone disorders; Malabsorption syndrome; and Pregnancy listed in the medical record.

Vitamin D test was performed by Enzyme-Linked Fluorescent Assay (ELFA) method using VIDAS. ${ }^{15}$

Ethical clearance in this study was obtained from the Commission for Research Ethics at the Dr. Soetomo Hospital with: 732/Panke.KKE/XII/2017.

\section{RESULTS AND DISCUSSION}

This study comprised 53 patients with schizophrenia from the Inpatient and Outpatient Clinic Department of Psychiatry of the Dr. Soetomo Hospital Surabaya. Sociodemographic and clinical data were collected, including age, sex, education, employment status, marital status, and early age were diagnosed with schizophrenia, and serum vitamin $D$ levels were shown in Table 1 . Their range age was 18 years to 49 years, with an average of $34.23 \pm 8.28$ years. There were 33 males (62.3\%).

The highest education was Senior High School (46.8\%), 41 patients (77.4\%) as unemployment. Most of the married status was unmarried 40 patients (75\%). The mean age of initial diagnosis of schizophrenia was $25.42 \pm 6.14$ years, range 11-44 years. The initial age of diagnosis of schizophrenia for males in the range 10-25 years was 26 patients (78.8\%).

The age peak of onset was 10 to 25 years for males and 25 to 35 years for females. This result may be because in females there is estrogen, a gonadal hormone that acts as a neuroprotective and a neurotransmitter that can regulate the dopaminergic system of the central nervous system, exert powerful effects in numerous regions of the brain, consequently affecting mood, cognition, and behaviour. ${ }^{16,17}$ In this study, the initial age of schizophrenia diagnosis in males range $10-25$ years were 26 patients (78\%) and females range 25-35 years were 17 patients ( $85 \%$ ) (Table 1 ). 
Table 1. Characteristics of study from 53 patients

\begin{tabular}{|c|c|}
\hline Characteristics & Number \\
\hline \multicolumn{2}{|l|}{ Age } \\
\hline Mean \pm SD & $34.23 \pm 8.29$ years \\
\hline Median & 34.00 years \\
\hline Range & $18-49$ years \\
\hline \multicolumn{2}{|l|}{ Sex N (\%) } \\
\hline Male & $33(62.3 \%)$ \\
\hline Female & 20 (37.7\%) \\
\hline \multicolumn{2}{|l|}{ Education, N (\%) } \\
\hline Junior High School & $3(5.7 \%)$ \\
\hline Senior High School & 46 (86.8\%) \\
\hline Scholar & $4(7.5 \%)$ \\
\hline \multicolumn{2}{|l|}{ Occupation, N (\%) } \\
\hline Employment & $12(22.6 \%)$ \\
\hline Unemployment & 41 (77.4\%) \\
\hline \multicolumn{2}{|l|}{ Marital Status,N (\%) } \\
\hline Married & $13(24.5 \%)$ \\
\hline Single & $40(75 \%)$ \\
\hline \multicolumn{2}{|l|}{ Age at disease onset $\mathrm{N}(\%)$} \\
\hline \multicolumn{2}{|l|}{ Male } \\
\hline 10-25 years & $26(78.8 \%)$ \\
\hline $26-50$ Years & 7 (21.2\%) \\
\hline \multicolumn{2}{|l|}{ Female } \\
\hline$<25$ years & $2(10 \%)$ \\
\hline 25-35years & 17 (85\%) \\
\hline $36-50$ years & $1(5 \%)$ \\
\hline \multicolumn{2}{|l|}{ PANSS scores } \\
\hline Positive symptoms (mean \pm SD); (minmax) & $16.42 \pm 8.50 ;(7-37)$ \\
\hline Negative symptoms (mean $\pm S D) ;(\min -m a x)$ & $15.60 \pm 6.12 ;(7-32)$ \\
\hline General psychopathology (mean $\pm S D) ;($ min-max) & $29.51 \pm 10.29 ;(16-62)$ \\
\hline
\end{tabular}

The results in this study showed that serum vitamin $D$ levels in schizophrenia subjects were $23.46 \pm 9.16 \mathrm{ng} / \mathrm{mL}$, these results indicated that serum vitamin $D$ levels were low in schizophrenia patients (Table 2). Previous studies had suggested that low prenatal vitamin $D$ adversely affect brain development and had an increased risk of developing schizophrenia later in life. ${ }^{18}$

Table 2. Vitamin D levels of schizophrenia patients

\begin{tabular}{cc}
\hline & Serum levels of vitamin D \\
\hline Mean & $23.46 \mathrm{ng} / \mathrm{mL}$ \\
SD & $9.16 \mathrm{ng} / \mathrm{mL}$ \\
Range & $8.1 \mathrm{ng} / \mathrm{mL}-44.5 \mathrm{ng} / \mathrm{mL}$ \\
\hline
\end{tabular}

These results indicated that serum vitamin $D$ levels were low in schizophrenia patients (normal vitamin D levels $=30-100 \mathrm{ng} / \mathrm{mL}$ ).

The finding of Vitamin D Receptors (VDR) in the central nervous system, in neurons and glial cells, further demonstrates the importance of vitamin $D$ in early development to obtain optimal brain function.
Conversely, the absence of vitamin $D$ in the embryonic brain results in increased levels of mitosis and decreased levels of apoptosis. Vitamin D plays a significant role in the cellular and transcriptional levels. Vitamin $D$ is also involved in the rate of cell proliferation and cell death in the brain. Structure and proliferation due to vitamin $D$ deficiency will be associated with abnormal neurochemistry and behavior in adulthood. ${ }^{18,11}$ Vitamin $D$ deficiency is also influenced by several factors such as; genetic, ethnic, age, seasonal and geographic factors, dietary intake of vitamin $D$, sunlight exposure and low economic status. ${ }^{19}$

The results of this study showed that serum vitamin D level in males was $24.36 \pm 9.80 \mathrm{ng} / \mathrm{mL}$ and females was $21.96 \pm 7.98 \mathrm{ng} / \mathrm{mL}$, there was no significant difference between serum vitamin $D$ levels in males and females ( $p=0.393$ ) (Table 3 ).

These results were consistent with the study of Cieslak et al. showing serum males vitamin D levels of $18.4 \pm 7.5 \mathrm{ng} / \mathrm{mL}$ and females $16.5 \pm 9.9 \mathrm{ng} / \mathrm{mL}^{20}$ Lally et al. obtained mean serum vitamin $D$ levels in 
males of $12.2 \pm 7 \mathrm{ng} / \mathrm{mL}$ and females $12.6 \pm 7.8$ $\mathrm{ng} / \mathrm{mL} .{ }^{21}$ Indonesia, especially the city of Surabaya, is a tropical area close to the equator and has only two seasons, rainy and dry season.

The geographical location is flat and just a few meters above sea level, the temperate climate can reach $33^{\circ} \mathrm{C}$, allowing each individual gets exposure to the sun. Pearce reported that sunlight exposure for 20 to 30 minutes on the face and forearms at midday was estimated to generate the equivalent of around 2,000 IU of vitamin $D^{22}$

The result of Spearman correlation test between serum vitamin D level and PANSS scores of positive symptoms showed a significance value of 0.823 $(p>0.005) ; r=0.032$, meaning there was no significant correlation between serum vitamin $D$ level and positive symptoms PANSS scores.

In this study serum, vitamin D levels were not correlated with positive symptoms of PANSS scores, mean positive symptoms PANSS scores in this study was $(16.42 \pm 8.50)$ (Figure 1). This finding was following studies conducted by Itzhaky et al., mean positive symptoms PANSS scores (19.6 \pm 11.8$)$, there was no significant correlation between serum vitamin D levels and PANSS score of positive symptoms. ${ }^{12}$ Likewise, with Lally et al. there was no significant correlation between vitamin $D$ levels and
PANSS scores of positive symptoms $(p=0.823) .{ }^{21}$ The results of the same study can be due to the research subjects taken mostly from the outpatient clinic, regardless of the duration of illness and episode of attack. The subjects of this study were schizophrenia patients who had received therapy, so had the same activities and lifestyle as healthy people and researchers did not consider the length of the subject suffering from schizophrenia.

The studies by Crews et al.reported there was a low serum vitamin $D$ correlation with increased severity of positive symptoms. ${ }^{23}$ Studies by Bulut et al. reported there was a correlation between low serum vitamin $D$ levels with the severity of positive symptoms. ${ }^{11}$ The subjects were schizophrenia patients who came with the first episode of psychotic attacks. Schizophrenia patients with a psychotic attack for the first episode have a habit of confining themselves so less exposed to sunlight, reduced activity, decreased appetite so did not get enough nutrition, especially vitamin $\mathrm{D}$.

The result of Pearson correlation test between serum vitamin D level and PANSS score of negative symptoms showed a significant value 0.964 $(p>0.005) ; r=0.006$, there was no significant correlation between serum vitamin $D$ level with negative symptoms PANSS scores.

Table 3. Serum vitamin D levels in males and females

\begin{tabular}{ccccc}
\hline & Mean & SD & Range & p \\
\hline Male & $24.36 \mathrm{ng} / \mathrm{mL}$ & $9.80 \mathrm{ng} / \mathrm{mL}$ & $8.1-44.5 \mathrm{ng} / \mathrm{L}$ & \\
Female & $21.96 \mathrm{ng} / \mathrm{mL}$ & $7.98 \mathrm{ng} / \mathrm{mL}$ & $10.3-35.9$ & 0.393 \\
\hline
\end{tabular}

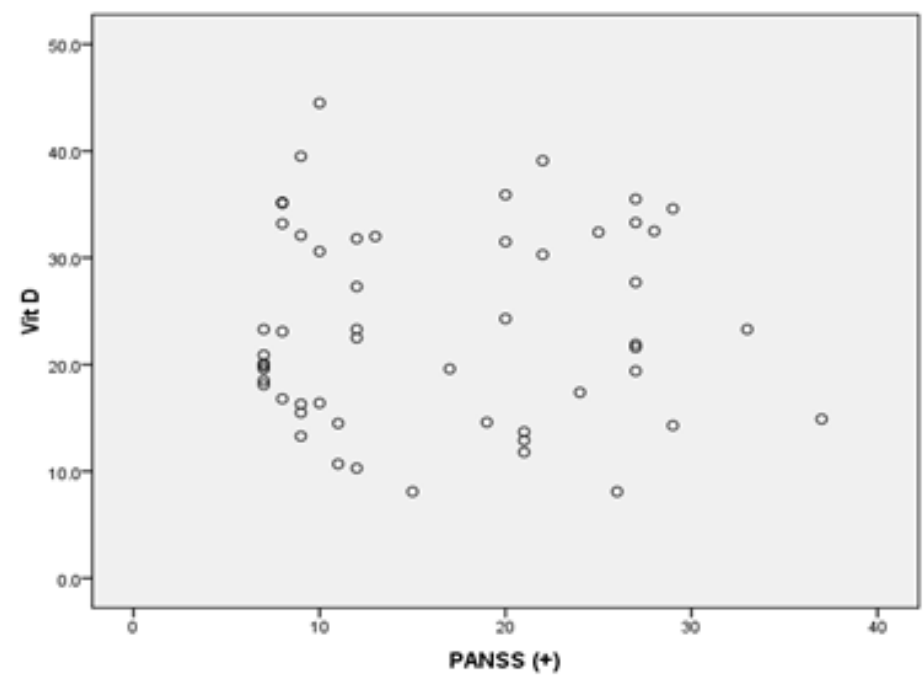

Figure 1. Serum vitamin D distribution with PANSS scores of positive symptoms 


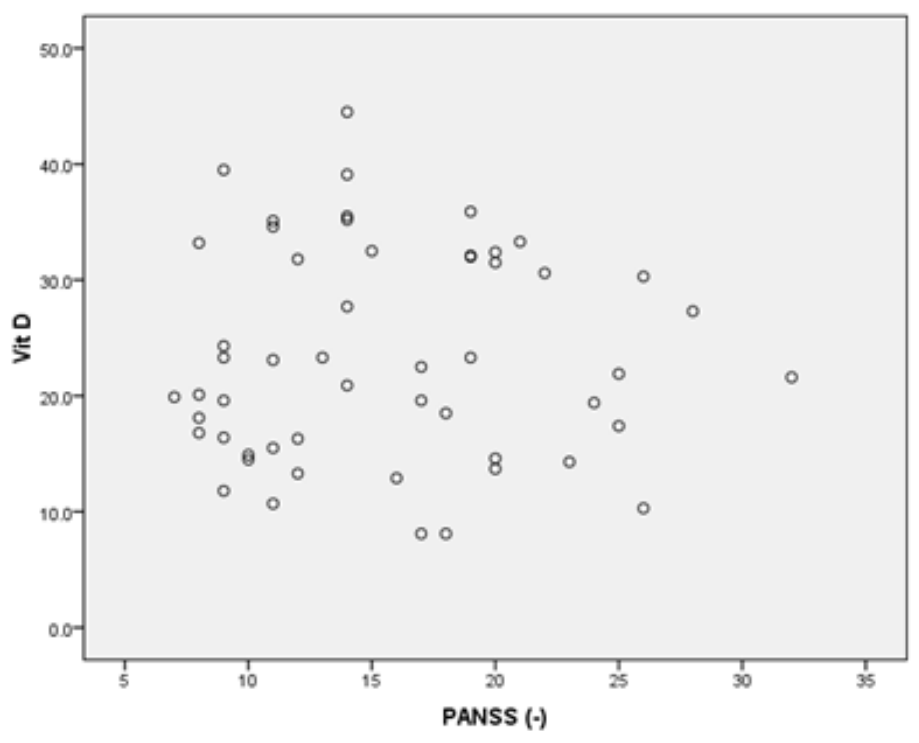

Figure 2. Serum vitamin D distribution with PANSS score of negative symptoms

The results of statistical analysis in this study showed no correlation between serum vitamin $D$ levels and PANSS scores of negative symptoms $(p=0.964)$ (Figure 2). This finding was following research of Itzhaky et al. there was no correlation between serum vitamin D levels and PANSS scores of negative symptoms $(p=0.066){ }^{12}$ Haddad et al. reported that there was no significant difference between serum vitamin D levels and PANSS score of negative symptoms $(p=0.680){ }^{24}$ This result may be because, in this study, subjects were mature schizophrenia patients (18 years-50 years) the majority who visited the Outpatient Clinic, taking antipsychotic drugs, had activities and lifestyle such as healthy people.

On the other hand, a study by Graham reported there was an association between low vitamin $D$ levels and the severity of negative symptoms. This difference might be because Graham's research subjects were adolescences with schizophrenia, who were still in the growing period, requiring more vitamin D intake for development. ${ }^{2}$ The Cieslak study reported that there was a relationship between vitamin $D$ levels and the severity of negative symptoms. The behavior of patients with negative symptoms was indicated by the presence of affective blunting, avolition/apathy, alogia, and disturbances of attention, leading to more deficient nutrition and less time spent outdoors that would contribute to lower vitamin D levels. ${ }^{20}$

Previous studies suggested that vitamin D involved in the pathogenesis of specific symptoms in schizophrenia. Wrzosek reported that vitamin D was neuroprotective through the prevention of oxidative stress in the central nervous system, and showed that oxidative stress caused negative symptoms through an imbalance in the excitative-inhibitory glutamate-GABA responses. ${ }^{25,26}$ Other studies have suggested that the decrease in glutamate (GLU) due to a dopamine deficit in the prefrontal cortex might lead to abnormalities of brain function associated with schizophrenia. A persistent defect in GLU transmission involving $\mathrm{N}$-methyl $\mathrm{D}$ aspartate receptors (NMDA) was induced by dopamine dysfunction. Decreased dopamine activity might aggravate the negative symptoms and impaired neurophysiological function. ${ }^{27}$

The result of Pearson correlation test between serum vitamin D level and PANSS scores of general symptom was showed a significant value 0.968 $(p>0.005) ; r=0.006$, meaning there was no significant correlation between serum vitamin $D$ level with general psychopathology PANSS scores. Serum vitamin D levels did not correlate with PANSS score of general psychopathology symptoms $(p=0.968)$, according to the study Itzhaky et al., there was no correlation between serum vitamin $D$ levels and PANSS scores. ${ }^{12}$ Haddad et al. reported there was no correlation between serum vitamin $D$ levels and PANSS scores of general psychopathology symptoms $(p=0.442) .{ }^{24}$ This finding could be due to the subjects of this study were obtained manly from the Outpatient Clinic (patients with mild disease symptoms) and had received treatment, whereas the previous studies recruited patients from hospitalization, which caused low levels of vitamin $D$, where patients have limited activity, so less exposed to sunlight (Figure 3). 


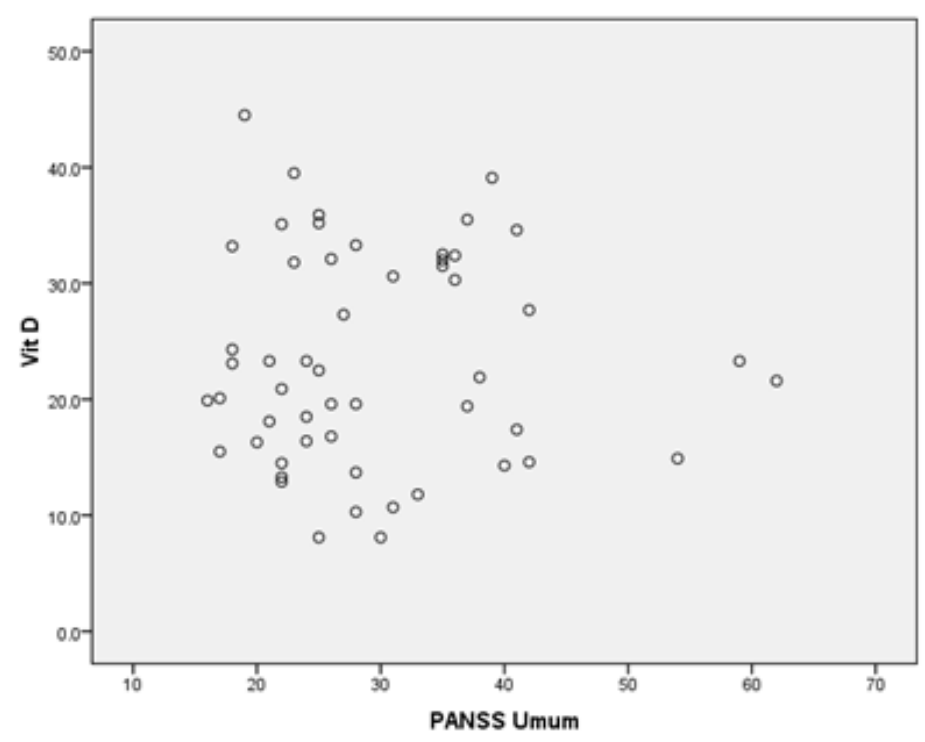

Figure 3. Serum vitamin D distribution with a PANSS score of general psychopathology symptoms

Different studies had reported by Yuksel, there was a correlation between vitamin D levels with PANSS score of general psychopathology symptoms. This difference was due to the grouping of the subjects between the remission and hospitalized patients. The hospitalized patients, there was a severe vitamin D deficiency and a high severity score compared with patients who had received treatment or remission. ${ }^{13}$

\section{CONCLUSION AND SUGGESTION}

There was no correlation between serum vitamin D levels, and PANSS score of positive symptoms, PANSS score of negative symptoms, and PANSS score of general psychopathology symptoms. This study was the first study to analyze the correlation between serum vitamin $D$ levels and schizophrenia severity. This research was an observational analytical study with a cross-sectional design. Further research is needed to look for various factors affecting serum vitamin $D$ levels and severity of schizophrenia patients, and investigate the association with longer follow up.

\section{ACKNOWLEDGMENTS}

The researchers are very grateful to the PT. ENSEVAL MEDIKA PRIMA for providing VIDAS $\otimes 25$ $\mathrm{OH}$ Vitamin D TOTAL kit and the Nursing Staff Department of Psychiatry for their support so that this study can be finished.

\section{REFERENCES}

1. Amaral AD, Calhau C, Coelho. Schizophrenia: Implication of vitamin $D$ deficit on brain development. Int J Clin Neurosci Ment Health, 2014, 1: 16-25.

2. Graham KA, Keefe RS, Lieberman JA, Calikoglu AS, Lansing KM, Perkins DO. Relationship of low vitamin D status with positive, negative and cognitive symptom domains in people with first-episode schizophrenia. J Intervent Psychiatry, 2015; 9: 397- 405.

3. Valipour G, Saneei P, Esmaillzadeh A. Serum vitamin D levels in relation to schizophrenia: A systematic review and meta-analysis of observational studies. J Clin Endocrinol Metab, 2014; 99(10): 3863-72.

4. Patel R K, Cherian J, Gohil K, Atkinson D. Schizophrenia: Overview and treatment options. P\&T Community, 2014; 39(9): 638-45.

5. Jablensky A, Sartorius N, Ernberg G, Anker M, Korten $A$, et al. Schizophrenia: Manifestations, incidence, and course in different cultures: A World Health Organization ten-country study. Cambridge, Cambridge University Press, 1992; 6-7.

6. Barbato A. Schizophrenia and public health. Division of mental health and prevention of substance abuse. World Health Organization. 1998; 3, 6-7.

7. Meli G, Ottl B, Paladini A, Cataldi L. Prenatal and perinatal risk factors of schizophrenia. J Matern Fetal Neonatal Med, 2012; 25(12): 2559-63.

8. Narr KL, Toga AW, Szeszko P. Cortical thinning in cingulate and occipital cortices in first episode schizophrenia. Biol Psychiatry, 2005; 58(1): 32-40.

9. McGrath JJ, Burne TH, Feron F, Mackay-Sim A, Eyles DW. Developmental vitamin D deficiency and risk of schizophrenia: A ten-year update. Schizophr Bull, 2011; 36: 1073-8.

10. Berg AO, Melle I, Torjesen PA, Lien L, Hauff E, 
Andreassen OA. A cross-sectional study of vitamin D deficiency among immigrants and Norwegians with psychosis compared to the general population. J Clin Psychiatry, 2010; 71(12): 1598-604.

11. Bulut SD, Bulut S, Atalan DG, Berkol T, Gurcay E, Turker $\mathrm{T}$, et al. The relationship between symptom severity and low vitamin D levels in patients with schizophrenia. Plos One, 2016; 11(10): 1-13.

12. Itzhaky $D, A$ mital $D$, Gorden K. Low serum vitamin $D$ concentrations in patients with schizophrenia. IMAJ, 2012; 14(2): 88-92.

13. Yüksel RN, Altunsoy N, Tikir B, Kuluk MC, Unal K, et al. Correlation between total vitamin $D$ levels and psychotic psychopathology in patients with schizophrenia: Therapeutic implications for add-on vitamin D augmentation. Ther Adv Psychopharmacol, 2014; 4(6): 268-275.

14. Arroll MA, Wilder $L$, Neil J. Nutritional interventions for the adjunctive treatment of schizophrenia: A brief review. Nutrition Journal, 2014; 13: 1-9.

15. Vidas ${ }^{\circledR} 25 \mathrm{OH}$ Vitamin $D$ Total assay. Biomerieux SA. 2015

16. Sadock BJ, Sadock VA. Schizophrenia spectrum and other psychotic disorders, in Kaplan \& Sadock's synopsis of psychiatry behavioral sciences/clinical psychiatry. 11thEd., Philadelphia, Lippincott Williams \& Wilkins, 2015; 288-315.

17. Gogos A, Sbisa AM, Sun J, Gibbons A, Udawela M, Dean B. A role for estrogen in schizophrenia: Clinical and preclinical findings. International Journal of Endocrinology,2015; 2015: 1-17.

18. Kesby JP, Cui Xiaoying, Burne THJ, Eyles DW. Altered dopamine ontogeny in the developmental vitamin D deficient rat and its relevance to schizophrenia. Frontiers in Cellular Neuroscience, 2013; 7(111): 1-12.

19. Sotodeh-AsI N, Tamadon M R, Malek F, Zahmatkesh M.Vitamin D deficiency and psychological disorders. J Parathyroid Dis, 2014; 2(1): 21-5.

20. Cieslak K, Feingold J, Antonius D, Messinger JW, Dracxler $\mathrm{R}$, et al. Low vitamin $\mathrm{D}$ levels predict clinical features of schizophrenia. National Institute of Health Public Acces, 2015; 1: 1-7.

21. Lally J, Gardner-Sood P, Firdosi M. Clinical correlates of vitamin D deficiency in established psychosis. BMC Psychiatry, 2016; 16: 1-9.

22. Pearce SH, Cheetham TD. Diagnosis and management of vitamin D deficiency. BMJ, 2010; 340.

23. Crews M, Lally J, Gardner-Sood P, Howes O, Bonaccorso $S$, et al. Vitamin $D$ deficiency in first episode psychosis: A case-control study. Schizophr Res, 2013; 150(2-3): 533-537.

24. Haddad C, Zoghbi M, Hallits S, Bou Assi T, Medlej Hasim M, Nabbout R, Azar J. Vitamin D levels in Lebanese patients with schizophrenia: A case-control study. Ann Nutri Dis Ther, 2017; 17: 1041-6.

25. Wrzosek M, Lukaszkiewicz J, Wrzosek M. Vitamin D, and the central nervous system. Pharmacological reports, 2013; 65(2): 271-8.

26. Albayrak Y, Unsal C, Beyazyuz M, Unal A, Kuloglu M. Reduced total antioxidant level and increased oxidative stress in patients with deficit schizophrenia: A preliminary study. Prog. Neuropsychopharmacol. Bol. Psychiatry, 2013; 45: 144-149.

27. Laruelle M. Schizophrenia: From dopaminergic to glutamatergic interventions. Curr Opin Pharmacol, 2014; 14: 97-102. 